\title{
Off-Label Treatment
}

National Cancer Institute

\section{Source}

National Cancer Institute. Off-Label Treatment. NCI Thesaurus. Code C125600.

The use of an FDA-approved device, drug, or treatment for a purpose other than that for which it was approved. 